\title{
PERILAKU PETANI MUDA DALAM AGRIBISNIS HORTIKULTURA DI KABUPATEN BANDUNG BARAT
}

\section{YOUNG FARMERS BEHAVIOR IN HORTICULTURE AGRIBUSINESS IN BANDUNG BARAT DISTRICT}

\section{Rani Andriani Budi Kusumo*, Gema Wibawa Mukti, Endah Djuwendah}

\author{
Program Studi Agribisnis Fakultas Pertanian Universitas Padjadjaran \\ J1. Raya Jatinangor Sumedang Km 21 \\ *Email: raniandriani081@gmail.com
}

(Diterima 27-08-2019; Disetujui 30-08-2019)

\begin{abstract}
ABSTRAK
Komoditas hortikultura merupakan komoditas yang dipandang memiliki peluang usaha yang cukup menjanjikan. Hal tersebut menarik minat generasi muda untuk kembali ke desa untuk berusaha di bidang pertanian, baik di sektor on farm maupun off farm. Penelitian ini bertujuan untuk mendeskripsikan perilaku petani muda dalam menjalankan agribisnis hortikultura di Kabupaten Bandung Barat. Penelitian ini dilakukan dengan pendekatan kuantitatif. Responden dalam penelitian ini berjumlah 120 orang dan merupakan petani yang berusia di bawah 40 tahun yang dipilih secara acak. Data dianalisis dengan menggunakan statistika deskriptif. Hasil penelitian menunjukkan secara umum perilaku petani muda dalam menjalankan agribisnis hortikultura tidak berbeda dengan generasi sebelumnya. Namun karakter yang menonjol dari petani muda dalam menjalankan agribisnis hortikultura adalah kemampuan petani dalam mencari informasi dan responsive terhadap perubahan dengan melakukan langkah-langkah yang inovatif. Untuk menjalankan usahatani petani dituntut tidak hanya ahli dalam proses produksi, namun juga harus memiliki kemampuan manajerial usaha yang berorientasi hasil.
\end{abstract}

Kata kunci: perilaku, agribisnis, petani, muda, hortikultura

\section{ABSTRACT}

Horticultural commodities are considered to have promising business opportunities. This has attracted the interest of young people to try in agriculture, both in the on farm and off farm sectors. This study aimed to describe the behavior of young farmers in doing horticultural agribusiness in Bandung Barat Regency. This research was conducted with a quantitative approach. Respondents in this study were 120 people and were farmers under the age of 40 with randomly selected. Data were analyzed using descriptive statistics. The results showed in general the behavior of young farmers in running horticultural agribusiness was not different from the previous generation. But the prominent character of young farmers in running horticultural agribusiness is the ability of farmers to find information and be responsive to change by taking innovative steps. To run a business, farmers are required not only to be experts in the production process, but also to have managerial skills in a results-oriented business.

Keywords: behavior, agribusiness, farmers, young, horticulture.

\section{PENDAHULUAN}

Komoditas hortikultura memberikan kontribusi yang cukup berarti dalam perekonomian nasional. Indikator tersebut dilihat dari sumbangan sektor hortikultura terhadap Produk Domestik Bruto (PDB), penyerapan tenaga kerja serta peningkatan volume dan nilai ekspror produk 
hortikultura. Agribisnis hortikultura (buah, sayur, tanaman hias dan tanaman obat) memiliki keunggulan berupa nilai jual yang tinggi, keragaman jenis, ketersediaan sumberdaya lahan dan teknologi, serta potensi pasar baik di dalam maupun luar negeri yang terus meningkat. Pasokan produk hortikultura nasional diarahkan untuk memenuhi kebutuhan konsumen dalam negeri, baik melalui pasar tradisional, pasar modern, maupun pasar ekspor (Dirjen Hortikultura, 2013).

Agribisnis hortikultura saat ini masih menghadapi berbagai kendala, diantaranya adalah rendahnya produksi, produktivitas dan kualitas hortikultura. Hal tersebut disebabkan oleh kapasitas SDM, kelembagaan, dan teknologi (Dirjen Hortikultura, 2013). Dari sisi sumberdaya manusia pertanian, umur petani merupakan salah satu faktor yang akan mempengaruhi keberlanjutan usahatani. Setiawan (2012) menjelaskan umur terkait erat dengan kemampuan psikologis, biologis, potensi dan tingkat kepekaan dalam menjalankan usahatani. Beberapa penelitian menunjukkan bahwa usia petani sangat terkait dengan kemampuan manajerial dalam usahatani (Zagata \& Sutherland, 2015), orientasi bisnis dan bisnis yang efisien (van Passel et al, 2007) serta pandangan tentang keberlanjutan usahatani (Comer et al, 1999).

Pemasalahan utama dalam sumberdaya manusia dalam bidang pertanian di Indonesia adalah struktur demografis petani yang lebih didominasi oleh petani berusia tua (lebih dari 55 tahun) dan di sisi lain jumlah tenaga kerja usia muda semakin berkurang (Susilowati, 2016). Data sensus pertanian tahun 2003 dan 2013 serta hasil survei pertanian antar sensus (SUTAS 2018) menunjukkan komposisi tenaga kerja pertanian didominasi oleh tenaga kerja yang berusia di atas 44 tahun (BPS 2003, 2013, 2018). Hal ini menunjukkan minat tenaga kerja muda untuk bekerja di sektor pertanian semakin berkurang. Selain itu, rendahnya tingkat pendidikan tenaga kerja di sektor pertanian juga masih menjadi permasalahan klasik di sektor pertanian (Susilowati, 2016).

Namun di sisi lain, fenomena tersebut merupakan suatu peluang yang sangat besar untuk bergerak di bidang pertanian. Dengan pangsa pasar yang semakin besar dan jumlah pelaku yang semakin sedikit, tentunya menjadi suatu tantangan dan peluang bagi seorang pebisnis yang hendak terjun di bidang agribisnis. Berkembangnya para pelaku muda di bidang agribisnis lebih terlihat di 
zona agroekosistem dataran tinggi yang berbasis komoditas hortikultura. Komoditas hortikultura dipandang memiliki peluang usaha yang cukup menjanjikan. Hal ini tentunya membawa harapan baru bagi keberlanjutan usaha pertanian. Banyak pemuda-pemuda yang kembali ke desa untuk berusaha di bidang pertanian, baik di sektor on farm maupun off farm, serta sektor agrokreatif (agrowisata, ekowisata, desa wisata, agroindustry kreatif). Mereka berusaha dalam skala mikro dan menengah (Rasmikayati, Setiawan, \& Saefudin, 2017).

Carter (2003) serta McElwee \& Bosworth, 2010), menyebutkan bahwa saat ini pertanian akan lebih baik apabila dikerjakan oleh generasi muda, karena petani yang lebih muda dan terlatih lebih baik dalam aktivitas bisnis yang lebih beragam, cenderung memiliki sikap positif terhadap peluang pasar yang baru, lebih peka terhadap Kebutuhan pelanggan, dan lebih siap untuk untuk terlibat dalam usaha baru.

Keberlanjutan agribisnis di masa yang akan datang sangat dipengaruhi oleh perilaku petani dalam menjalankan usahanya. Gambaran mengenai perilaku petani muda dalam menjalankan agibisnisnya diperlukan sebagai upaya untuk memperbaiki dan meningkatkan perilaku agribisnis secara menyeluruh dari mulai proses produksi hingga pemasaran.

\section{METODE PENELITIAN}

Penelitian dilaksanakan di Kabupaten Bandung Barat yang merupakan salah satu kabupaten dengan jumlah petani sayuran organik terbanyak di Jawa Barat (BPS, 2016). Kecamatan yang menjadi tempat penelitian adalah Cisarua, Parongpong dan Lembang. Penelitian ini berfokus pada petani muda yang terdapat di ketiga kecamatan tersebut dengan kepemilikan lahan tidak lebih dari dua hektar (skala kecil). Penelitian ini menggunakan metode penelitian kuantitatif. Pendekatan kuantatif digunakan untuk lebih memahami fakta sosial yang menjadi fokus penelitian (Singarimbun \& Effendi, 2008).

\section{Jenis Data dan Teknik Pengumpulan Data}

Data yang digunakan dalam penelitian ini adalah data primer dan data sekunder. Data primer merupakan data yang diperoleh langsung dari petani muda yang memiliki usaha dalam bidang pertanian komoditas hortikultura di wilayah Kabupaten Bandung Barat. Sedangkan data sekunder dari Badan 
Pusat Statistik, Jurnal, buku dan sumber data lainnya.

Teknik pengumpulan data dilakukan melalui :

1. Wawancara (interview) dengan panduan kuesioner, yaitu melakukan komunikasi langsung secara verbal dengan menggali permasalahan

2. Pengamatan langsung (observasi), yaitu pengamatan langsung dilakukan untuk melihat lokasi objek penelitian serta melakukan pengumpulan data sekunder. Observasi ini juga dilakukan secara mendalam, dengan mengikuti kegiatan petani secara penuh dalam aktivitas usaha,

3. Studi pustaka dari jurnal bereputasi sebagai acuan untuk menganalisis data yang dihasilkan di lapangan.

Dalam penelitian ini variabel yang akan diteliti adalah:

1. Karakteristik petani muda meliputi: umur, tingkat pendidikan, pengalaman usahatani, luas dan status penguasaan lahan.

2. Perilaku petani muda adalah tindakan atau aktivitas yang dilakukan petani dalam menjalankan agribisnis hortikultura, diukur melalui melalui item pertanyaan dengan 5 poin Skala Likert.

\section{Pemilihan Sampel}

Penentuan sampel dilakukan dengan metode systematic random sampling. Untuk mendapatkan validitas yang tinggi, maka penentuan sampel sangat penting dalam penelitian ini. Strata dalam penelitian ini adalah petani muda yang berusia di bawah 40 tahun, berusahatani dalam sub bidang produk hortikultura di Kabupaten Bandung Barat. Kecamatan yang dipilih adalah kecamatan Lembang, Parongpong dan Cisarua. Pemilihan ketiga kecamatan tersebut dikarenakan ketiga kecamatan tersebut merupakan sentra hortikultura di Kabupaten Bandung Barat. Langkah selanjutnya adalah mengambil jumlah petani secara proporsional dari setiap kecamatan, sehingga total sample yang diteliti dalam penelitian ini adalah sebanyak 120 orang petani muda.

\section{Rancangan Analisis Data}

Analisis data ini dilakukan dengan menggunakan statistik deskriptif. Data yang diperoleh kemudian dikumpulkan dalam bentuk tabel distribusi frekuensi, disajikan, dianalisis dan diinterpretasikan untuk melihat perilaku petani muda pada agribisnis hortikultura di Kabupaten Bandung Barat. 
HASIL DAN PEMBAHASAN

Karakteristik Petani Muda

Berbagai definisi menyebutkan batasan usia petani muda, namun mayoritas menyebutkan bahwa petani muda adalah petani dengan kelompok umur di bawah 35 tahun (Zagata \& Sutherland, 2015). Sebagian besar petani muda di Kabupaten Bandung Barat berumur 31-40 tahun, dengan rata-rata umur petani adalah 34 tahun. Hal ini menunjukkan bahwa usahatani hortikultura di Kabupaten Barat mulai banyak dilakukan oleh petani berusia muda (Tabel 1).

Tabel 1. Karakteristik Petani Muda di Kabupaten Bandung Barat

\begin{tabular}{lrr}
\hline \multicolumn{1}{c}{ Karakteristik } & Jumlah (n) & Persentase (\%) \\
\hline Umur (Tahun) & 21 & \\
\hline $21-30$ & 99 & \\
\hline $31-40$ & 34,67 tahun & \\
\hline Rata-rata umur & & 17,50 \\
\hline Pendidikan Formal & 22 & 18,33 \\
\hline Tamat SD & 43 & 35,83 \\
\hline Tamat SMP & 36 & 30,00 \\
\hline Tamat SMA & 4 & 3,33 \\
\hline Akademi & 15 & 12,50 \\
\hline Sarjana & & 50,83 \\
\hline Status Penguasaan Lahan & 61 & 49,17 \\
\hline Milik & 59 & \\
\hline Sewa & & 68,33 \\
\hline & & 21,67 \\
\hline Luas Penguasaan Lahan (Ha) & 82 & 10,00 \\
\hline$<0,5$ & 26 & \\
\hline $0,5-1$ & 12 & \\
\hline$>1$ & & \\
\hline
\end{tabular}

Fenomena yang menarik adalah terdapat kecenderungan sektor hortikultura mulai diminati oleh petani muda dengan latar pendidikan yang tinggi, meskipun persentasenya lebih kecil dibandingkan dengan petani yang menempuh pendidikan formal hanya hingga tingkat SMP. Tingkat pendidikan petani yang lebih baik tentunya membawa harapan petani akan memiliki kemampuan untuk mengelola usahatani dengan lebih baik dan mampu berinovasi dalam usaha yang mereka jalankan, serta memiliki konsep dan model bisnis yang jelas (Mukti, Kusumo, \& Qanti, 2017).

Sebagian petani $(50,83 \%)$ berusahatani di lahan milik sendiri. Berdasarkan penuturan responden, sebagian petani mewarisi lahan dari orangtuanya meskipun luasannya terbatas. Bagi petani muda dan baru memulai usahanya, akses terhadap lahan menjadi tantangan tersendiri untuk memulai usahatani (Katchova \& Ahearn, 2016). 
Petani muda mengatasi keterbatasan mereka terhadap kepemilikan lahan dengan cara menyewa lahan dan juga melakukan sistem bagi hasil dengan pemilik lahan. Sebagian besar petani $(68,33 \%)$ menguasai lahan $<0,5 \mathrm{Ha}$.

\section{Perilaku Agribisnis Petani Muda di Kabupaten Bandung Barat}

Perilaku Agribisnis petani muda diukur melalui perilaku petani dalam setiap sub sistem agribisnis, yaitu sub sistem penyediaaan sarana produksi, budidaya, penanganan panen dan pasca panen, pemasaran serta sub sistem jasa penunjang.

Dalam sub sistem pengadaan sarana produksi, sebagian besar petani $(80 \%)$ mendapatkan input produksi seperti pupuk dan pestisida dengan cara membeli di toko pertanian. Sementara itu, sebagian petani yang melakukan usahatani dengan sistem bagi hasil, mereka mendapatkan sarana produksi dari pemilik lahan, sesuai dengan perjanjian bagi hasil yang telah disepakati. Untuk tenaga kerja, sebagian besar petani (73,34\%) menggunakan tenaga kerja dari luar keluarga, Ketersediaan modal merupakan tantangan tersendiri bagi petani muda yang baru memulai usahanya. Sebagian besar petani mengatakan masih kesulitan mengakses modal dari lembaga perbankan karena mereka tidak memiliki jaminan sebagai salah satu persyaratan dalam mengajukan kredit. Hal serupa juga disebutkan oleh Katchova \& Ahearn (2016) pada kasus petani muda dan pemula di Amerika Serikat, bahwa keterbatasan akses terhadap kredit menjadi salah satu kendala bagi petani muda; petani memerlukan modal diperlukan untuk memperluas skala usaha yang petani jalankan. Sebagian besar petani $(90 \%)$ memperoleh modal dari diri sendiri atau berpatungan dengan rekan bisnis. Untuk petani yang memiliki mitra, biasanya mereka mendapatkan modal dari mitra bisnis (Tabel 2).

Tabel 2. Perilaku Petani Muda dalam Sub Sistem Pengadaan Sarana Produksi Pertanian

\begin{tabular}{lcr}
\hline \multicolumn{1}{c}{ Sarana Produksi Pertanian } & Jumlah (n) & Persentase (\%) \\
\hline Sumber Saprotan & & \\
\hline Beli & 96 & 80,00 \\
\hline Diberi oleh pemilik lahan & 24 & 20,00 \\
\hline Tenaga Kerja & 32 & 26,67 \\
\hline Dalam keluarga & 88 & 73.34 \\
\hline Luar keluarga & & \\
\hline Sumber Modal & 108 & 90,00 \\
\hline Sendiri & 2 & 1,67 \\
\hline Pinjaman lembaga keuangan & 2 & 1,67 \\
\hline Pinjaman kerabat & 8 & 6,67 \\
\hline Mitra & & \\
\hline
\end{tabular}


Sebagian petani membudidayakan komoditas hortikultura bernilai ekonomis tinggi, dan juga mengikuti pola tanam tertentu mengikuti permintaan pasar. Oleh karenanya diperlukan teknologi budidaya agar tanaman yang mereka usahakan memberikan hasil panen yang maksimal. Teknologi yang banyak digunakan oleh petani adalah budidaya dengan sistem hidroponik dan penggunaan screen house. Sementara, sebagian petani lain tidak menggunakan teknologi tertentu dalam budidaya, berdasarkan hasil wawancara petani mengaku belum memiliki modal yang cukup untuk menerapkan teknologi budidaya.

Sebagian besar petani belum
Dalam hal pengendalian organisme pengganggu tanaman dan penggunaan pupuk, petani masih menggunakan input kimia (Tabel 3). Hanya sebagian kecil petani yang menerapkan sistem pertanian organik, hal ini didorong oleh permintaan pasar yang menginginkan produk ramah lingkungan dan bagi sebagian petani, kesadaran akan pentingnya menjaga keberlanjutan ekosistem merupakan faktor yang mempengaruhi petani untuk menerapkan sistem pertanian organik. Ameriana (2008) menyebutkan pengetahuan petani terhadap bahaya input kimia berpengaruh terhadap keputusan petani untuk menggunakan pestisida kimia. menerapkan sistem pertanian organik.

Tabel 3. Perilaku Petani Muda dalam Subsistem Budidaya Tanaman Hortikultura

\begin{tabular}{|c|c|c|}
\hline Kegiatan Budidaya & Jumlah (n) & Persentase (\%) \\
\hline \multicolumn{3}{|l|}{ Menggunakan Teknologi Budidaya } \\
\hline Ya & 54 & 45,00 \\
\hline Tidak & 66 & 55,00 \\
\hline \multicolumn{3}{|l|}{ Pengendalian OPT } \\
\hline Menggunakan pestisida kimia & 112 & 93,33 \\
\hline Non kimia & 8 & 6,67 \\
\hline \multicolumn{3}{|l|}{ Penggunaan pupuk } \\
\hline Pupuk kimia & 105 & 87,50 \\
\hline Pupuk organik & 15 & 12,50 \\
\hline
\end{tabular}

Pada kegiatan pasca panen, sebagian besar petani melakukan kegiatan sortasi $(63,33 \%)$ dan grading $(36,67 \%)$ (Tabel 4). Petani mengatakan bahwa konsumen (konsumen akhir ataupun mitra) menginginkan produk dalam grade tertentu, sehingga mereka melakukan kegiatan sortasi dan grading. Sebagian petani tidak melakukan kegiatan sortasi dan grading karena mereka menjual produknya ke bandar yang membeli 
dengan sistem abresan ${ }^{1}$. Baru sebagian kecil petani yang melakukan kegiatan pengemasan $(37,50 \%)$ dan pelabelan (10\%). Hal ini dikarenakan sebagian besar petani menjual hasil panennya ke bandar. Petani yang melakukan kegiatan pengemasan dan juga pelabelan biasanya adalah petani yang menjual langsung hasil panennya pada konsumen akhir dan juga kepada pedagang perantara ataupun mitra yang memang menginginkan produk yang sudah dikemas. Di Desa Cibodas Kecamatan Lembang terdapat packaging house yang dikelola oleh desa, dan petani ataupun kelompok tani dapat melakukan aktivitas pengemasan di sana.

Tabel 4. Perilaku Petani Muda dalam Subsistem Pasca Panen

\begin{tabular}{llr}
\hline \multicolumn{1}{c}{ Kegiatan Pasca Panen } & Jumlah (n) & Persentase (\%) \\
\hline Melakukan Sortasi & & \\
\hline Ya & 76 & 63,33 \\
\hline Tidak & 44 & 36,67 \\
\hline Melakukan Grading & & \\
\hline Ya & 65 & 54,17 \\
\hline Tidak & 55 & 45,83 \\
\hline Melakukan Pengemasan & & 37,50 \\
\hline Ya & 45 & 62,50 \\
\hline Tidak & 75 & \\
\hline Melakukan Pelabelan & & 10,00 \\
\hline Ya & 12 & 90,00 \\
\hline Tidak & 108 & \\
\hline
\end{tabular}

Seperti telah dibahas sebelumnya, sebagian besar petani $(80,83 \%)$ menjual hasil panennya ke bandar. Namun fakta yang menarik adalah ada beberapa petani yang mulai merintis sistem penjualan langsung ke pasar atau konsumen akhir. Petani muda memperkenalkan dan menjual produknya dengan cara yang inovatif yaitu menggunakan media sosial, dimana untuk konsumen terutama konsumen perkotaan penggunaan media sosial merupakan bagian yang tidak

\footnotetext{
${ }^{1}$ Abresan : istilah lokal untuk penjualan hasil panen tanpa melakukan sortasi dan grading.
}

terpisahkan dalam kehidupan sehari-hari (Mukti et al., 2017).

Petani muda relatif lebih cepat dan mudah dalam mencari informasi pasar, terlebih ditunjang oleh kemajuan teknologi informasi yang memudahkan petani muda untuk memperoleh informasi. Sebagian besar petani (93,33\%) mengetahui informasi pasar terkait dengan perkembangan harga dan juga permintaan komoditas. Hal ini sejalan dengan kajian Mukti et al (2017) yang menyebutkan bahwa petani muda lebih dapat mengikuti

Semua grade dicampur dan diberi harga yang sama 
kebutuhan pasar dengan cepat sehingga mereka lebih responsif mengikuti keinginan konsumen. Sukayat \& Supyandi, (2017) menyebutkan petani muda memiliki orientasi ekonomi yang tinggi, sehingga petani muda lebih gencar dalam mencari informasi dan peluang serta melakukan usaha-usaha yang inovatif untuk memaksimalkan pendapatan dan mengembangan usahanya.

Tabel 5. Perilaku Petani Muda dalam Subsistem Pemasaran

\begin{tabular}{lrr}
\hline \multicolumn{1}{c}{ Kegiatan Pemasaran } & Jumlah (n) & Persentase (\%) \\
\hline Pemasaran & 11 & 9,17 \\
\hline Langsung ke pasar & 97 & 80,83 \\
\hline Melalui bandar/pedagang pengumpul & 7 & 5,83 \\
\hline Melalui kelompok tani & 5 & 4,17 \\
\hline Melalui mitra & & \\
\hline Mengetahui informasi pasar & 112 & 93,33 \\
\hline Ya & 8 & 6,67 \\
\hline Tidak & 8 & \\
\hline
\end{tabular}

Sebagian besar petani $(74,17 \%)$ tergabung dalam kelompok tani (Tabel 6). Petani menilai kelompok tani berperan sebagai wahana belajar dan bertukar informasi serta memperluas jaringan. (Mailfert, 2007) menyebutkan bagi petani muda yang baru terlibat dalam usaha pertanian, jaringan sosial merupakan faktor penting untuk memperoleh dukungan materi ataupun non materi dalam menjalankan usahatani. Selain kelompok tani, saat ini mulai tumbuh komunitas kreatif pedesaan yang merupakan wadah para petani untuk saling berkolaborasi dan berkoordinasi dengan berbagai pihak terkait. Hal ini tentunya menjadi modal sosial bagi para petani muda untuk menjalankan usahanya (Rasmikayati et al., 2017). Lebih lanjut dikatakan bahwa berbisnis dan membangun jaringan menjadi suatu tuntutan bagi petani dalam menjalankan usaha mereka sebagai suatu tindakan rasional bagi petani dengan skala usaha kecil sehingga mereka dapat memasuki pasar dengan efisiensi kolektif (Mesquita \& Lazzarini, 2008).

Baru sebagian petani $(55,83 \%)$ yang mengakses lembaga keuangan baik formal maupun non formal (Tabel 4) . Seperti dijelaskan sebelumnya, bagi petani yang belum bisa mengakses lembaga keuangan, modal diperoleh dengan mengandalkan jaringan yang dimiliki serta berpatungan dengan rekan kerja. Mukti et al. (2017) menjelaskan banyak petani muda yang menjalankan usahanya secara berkelompok, dengan tujuan agar lebih 
mudah berbagi informasi, berbagi peran dan juga berbagi resiko dalam usahatani.

Dalam kegiatan penyuluhan, sebagian besar petani (65\%) tidak pernah mengikuti kegiatan penyuluhan. Hal ini dikarenakan di daerah penelitian relatif jarang dilakukan kegiatan penyuluhan secara massal dari pemerintah.

Tabel 6. Perilaku Petani Muda dalam Subsistem Lembaga Penunjang

\begin{tabular}{lrr}
\hline \multicolumn{1}{c}{ Lembaga Penunjang } & Jumlah (n) & Persentase (\%) \\
\hline Tergabung Dalam Kelompok Tani & & \\
\hline Ya & 89 & 74,17 \\
\hline Tidak & 31 & 25,83 \\
\hline Bermitra & 7 & 5,83 \\
\hline Ya & 113 & 94,17 \\
\hline Tidak & & \\
\hline Mengakses lembaga keuangan & 67 & 55,83 \\
\hline Ya & 53 & 44,17 \\
\hline Tidak & & \\
\hline Mengikuti Penyuluhan & 42 & 35,00 \\
\hline Ya & 78 & 65,00 \\
\hline Tidak & 78 & \\
\hline
\end{tabular}

\section{KESIMPULAN DAN SARAN}

Perilaku yang menonjol dari petani muda dalam menjalankan agribisnis hortikultura adalah kemampuan petani dalam mencari informasi dan responsive terhadap perubahan dengan melakukan langkah-langkah yang inovatif sehingga komoditas yang dihasilkan dapat memenuhi permintaan konsumen. Dapat dikatakan perilaku tersebut merupakan karakter dari seorang entrepreneur. Petani yang berperan sebagai entrepreneur tidak hanya ahli dalam proses produksi, namun mereka memiliki kemampuan manajerial usaha yang visioner berorientasi hasil

\section{DAFTAR PUSTAKA}

Ameriana, M. (2008). Perilaku Petani Sayuran dalam Menggunakan Pestisida Kimia. Jurnal
Hortikultura, 18(1), 95-106.

Carter, S. L. (2003). Entrepreneurship In The Farm Sector: Indigenous Growth For Rural Areas. In Entrepreneurship In Regional Food Production, pp. 23-50. Norway : Norland Research Institute.

Comer, S., Ekanem, E., Muhammad, S., Singh, S., Tegegne, F. (1999). Sustainable and Conventional Farmers : a Comparasioan of Socioeconomis Characteristics, Attitude and Beliefs. J Sustain. Agric, 15, 2945.

Direktorat Jenderal Hortikultura. (2013). Rencana Kinerja Tahunan (RKT) Direktorat Jenderal Hortikultura. (diunduh tanggal 11 Juli 2019).

Katchova, A. L., \& Ahearn, M. C. (2016). Dynamics of Farmland Ownership and Leasing: Implications for Young and Beginning Farmers 1. Applied Economic Perspectives and Policy, 38(2), 334-350. https://doi.org/10.1093/aepp/ppv02 4

Mailfert, K. (2007). New Farmers And Networks : How Beginning Farmers 
Build Social Connections In France. Economische en Sociale Geografie 98(1), 21-31.

McElwee, G., \& Bosworth, G. (2010). Exploring The Strategic Skills of Farmers Across A Typology Of Farm Diversification Approaches. Journal of Farm Management, 13(12), 819-838.

Mardikanto, Totok, (2008). Aspek Sumberdaya Manusia dalam Pengembangan Agribisnis Hortikultura. Agritech, X(1), 1-6

Mesquita, L. F. \& Lazzarini, S. G. (2008). Horizontal And Vertical Relationships In Developing Economies: Implications For Smes' Access To Global Markets. Academy of Management Journal, 51(2), 359-380.

Mukti, G. W., Kusumo, R. A. B., \& Qanti, S. R. (2017). Perilaku Sukses Petani Muda Wirausaha Lulusan Fakultas Pertanian Universitas Padjadjaran. Agribisnis Terpadu, 10(2), 221234.

Rasmikayati, E., Setiawan, I., \& Saefudin, B. R. (2017). Kajian Karakteristik, Perilaku Dan Faktor Pendorong Petani Muda Terlibat Dalam Agribisnis Pada Era Pasar Global. Mimbar Agribisnis, 3(2), 134-149.
Setiawan, I. (2012). Agribisnis Kreatif: Pilar Wirausaha Masa Depan, Kekuatan Dunia Baru Menuju Kemakmuran Hijau. Jakarta: Penebar Swadaya.

Sukayat, Y., \& Supyandi, D. (2017). Perilaku Pemuda Desa Dalam Kegiatan Pertanian ( Beberapa Kasus Pemuda Desa di Agroekosistem Dataran Tinggi, Dataran Medium dan Dataran Rendah ). Agrivet, 5(1), 49-55.

Susilowati, S. H. (2016). Fenomena Penuaan Petani Dan Berkurangnya Tenaga Kerja Muda Serta Implikasinya Bagi Kebijakan Pembangunan Pertanian. Forum Penelitian Agro Ekonomi, 34(1), 35-55.

Van Passel, S., Nevens, F., Mathijs, E., Van Huylenbroeck, G. (2007). Measuring Farm Sustainability and Explaining Differences in Sustainable Efficiency. Ecol.Econ, 62, 149-161

Zagata, L., \& Sutherland, L. (2015). Deconstructing the "young farmer problem in Europe ': Towards a research agenda. Journal of Rural Studies, 38(1), 39-51. https://doi.org/10.1016/j.jrurstud.20 15.01.003 